\title{
EDGAR MORIN EN ESTUDIOS
}

\section{$E_{n}$ algún momento, Edgar Morin} escribió, con razón, que el pensador Cornelius Castoriadis era un titán del espíritu. No es desacertado decir que Edgar Morin es un coloso del pensamiento, pues es la cabeza más universal de nuestro tiempo. Alimentado por su infinita curiosidad y su implacable voluntad de conocer, Morin ha indagado en numerosos dominios científicos, intelectuales, literarios, artísticos. En algunos de ellos ha profundizado de tal manera que ha llevado a cabo verdaderas inflexiones en las formas habituales de reflexionar. En otros, ha restablecido o creado interrelaciones que se habían suprimido o que no existían entre diversos campos del conocimiento. Ha redefinido y creado nuevos conceptos para aproximarse con mayor precisión a nuevas realidades.

Hace unos meses, en una conversación con él sobre el sentido de las palabras, cuestionamos la acepción que se sigue dando a conceptos como independencia y revolución. En el primer caso, se ha abusado de una palabra que designó un movimiento social, político y económico muy preciso: el que condujo a la independencia de los EUA. Después de su guerra con Inglaterra, Estados Unidos fue la única colonia europea en América que se convirtió en una nación realmente independiente. Otros países vivieron un proceso que se supuso semejante, en Hispanoamérica, primero, y más tarde en Asia y en África, pero nunca han llegado a ser totalmente independientes. En el segundo caso, el concepto designa 
un cambio social, político, intelectual y cultural muy preciso: el de la Revolución francesa. Al igual que ocurrió con la palabra independencia, la voz revolución ha sido usada de manera arbitraria para designar procesos sociales que no sólo no dieron lugar a algo realmente nuevo, sino que aun impidieron posibles transformaciones. La revolución bolchevique no cambió nada. Esto lo confirma el hecho de que, después del derrumbe del imperio soviético, la mayoría de los rusos volvió a vivir como en tiempos de los zares. La revolución mexicana de 1910 nunca produjo cambios realmente significativos. O sí, pero de manera análoga a lo que ocurrió en la URSS, dado que construyó una nueva modalidad de la dictadura: la del partido único, basado en un aparato corporativo que todavía hoy se mantiene en pie. Además, los comportamientos de los oligarcas de hoy no son muy diferentes a los de los oligarcas de hace cien años. Hablar de revolución en nuestros días carece de sentido. Morin propone, en cambio, hablar de metamorfosis, a propósito de los cambios que lenta y cotidianamente se producen día a día y, sobre todo, inesperadamente, en el interior de cada sociedad, en las personas y en las relaciones de unas con otras. Elige esta palabra por una sencilla razón: mantiene la identidad en la alteridad, implica transformación y conservación al mismo tiempo. Piensa que, pese a los símbolos de catástrofe que hoy se observan por doquier (medio ambiente, pobreza, guerras, intolerancias religiosas) aún es posible una metamorfosis y no precisamente una revolución.

Morin ha creado un recurso extraordinario para acercarse al conocimiento de la relaciones entre los diversos campos del saber, y entre éstos y las diversas prácticas sociales: el pensamiento complejo, del cual da cuenta en una conferencia que reproducimos en este número de Estudios. Acompañan este texto trabajos de la brasileña Çeica Almeida, del cubano Carlos Delgado, del francés Jean Tellez y del colombiano Gabriel Restrepo Forero, que ganó el primer lugar en el Premio Internacional Edgar Morin-88 años.

México, enero de 2010 Julián Meza 